\title{
Distribution of Mean Cycle Length in Cavo-Tricuspid Isthmus Dependent Atrial Flutter
}

\author{
Š. HAVRÁNEK ${ }^{1}$, J. ŠIMEK ${ }^{1}$, P. ŠŤOVÍČEK ${ }^{1}$, D. WICHTERLE ${ }^{1,2}$ \\ ${ }^{1}$ Second Department of Medicine - Department of Cardiovascular Medicine, First Faculty of \\ Medicine, Charles University in Prague and General University Hospital in Prague, ${ }^{2}$ Department of \\ Cardiology, Institute for Clinical and Experimental Medicine, Prague, Czech Republic
}

Received April 3, 2011

Accepted August 19, 2011

On-line December 20, 2011

\section{Summary}

Although cycle length (CL) constitutes a fundamental descriptor of any arrhythmia, there is not larger study describing mean $\mathrm{CL}$ in electrophysiologically confirmed cavo-tricuspid isthmus (CTI)dependent atrial flutter (AFL). We analyzed retrospectively digital recordings of 121 patients (98 men; age $64 \pm 11$ years) referred for radiofrequency ablation of persistent CTI-dependent AFL. Median of mean AFL CL was 240 ms (interquartile range (IQR) of 222-258 ms, overall range of 178-399 ms). The distribution of $\mathrm{CL}$ was not normal (Shapiro Wilk test, $\mathrm{p}<0.001$ ). Both counterclockwise and clockwise (14.9\% of all cases) AFLs were comparable in their CL; 240 (IQR 222-258) ms vs. 234 (217-253) ms, respectively. $\mathrm{AFL} \mathrm{CL}<200 \mathrm{~ms}$ and $\mathrm{AFL} \mathrm{CL}<190 \mathrm{~ms}$ was noticed in $5(4.1 \%)$ and 3 cases $(2.5 \%)$, respectively. In multivariate regression analysis, age (increase by $6 \pm 3 \mathrm{~ms}$ per decade of age, $p=0.036$ ), treatment with specific antiarrhythmic drugs (increase by $11 \pm 6 \mathrm{~ms}, \mathrm{p}=0.052$ ) and the history of cardiac surgery (increase by $26 \pm 9 \mathrm{~ms}, \mathrm{p}=0.004$ ) were independently associated with AFL CL. In conclusions, the distribution of AFL CL is not normal. The prevalence of AFL with short $C L$ is low. Short $\mathrm{CL}<200 \mathrm{~ms}$ does not rule out the CTI-dependent AFL, especially in young and otherwise healthy patients.
\end{abstract}

\section{Key words}

Arrhythmia cycle length • Cavo-tricuspid isthmus-dependent atrial flutter • Catheter ablation

\section{Corresponding author}

Stepan Havranek, Second Department of Medicine - Department of Cardiovascular Medicine, First Faculty of Medicine, Charles University and General University Hospital in Prague, U Nemocnice 2, 12808 Prague, Czech Republic. Fax: +420 224912 154. E-mail: stepan.havranek@If1.cuni.cz

\section{Introduction}

Cavo-tricuspid isthmus (CTI)-dependent atrial flutter (AFL) is a right-atrial macro-reentrant tachycardia with the circuit bounded anteriorly by the tricuspid annulus and, posteriorly, by the venae cavae orifices, Eustachian ridge, and by the functional barrier of the crista terminalis (Feld et al. 1992, Olgin et al. 1995, Shah et al. 1997, Fukuzawa et al. 2008, Santucci et al. 2009, Gami et al. 2010). Radiofrequency catheter ablation of CTI is curative approach for both counterclockwise (CCW) and clockwise (CW) variants of CTI-dependent AFL (Feld et al. 1992, Waldo 2000, Cosio et al. 1993).

In clinical practice, the diagnosis of CTIdependent AFL is based on the presence of characteristic sawtooth AFL waves in inferior ECG leads, low amplitude biphasic AFL waves in leads I and aVL, and upright AFL waves in V1 with transition to negative F waves in V6. However, atypical ECG pattern does not rule out CTI-dependent AFL (Barbato et al. 2009). This is particularly evident in case of CW CTI-dependent AFL, which displays more variable ECG patterns than more frequent CCW variant (Cosio et al. 1993, Waldo et al. 1997, Waldo 2000). Similarly, when atria are significantly affected by spontaneous or post-ablation scarring the morphology of F-waves may become "atypical" even in the case of CTI-dependent CCW AFL. On the other hand, atrial fibrillation with significant leftto-right gradient of dominant frequency may falsely suggest the CTI-dependent AFL. While an invasive electrophysiological study is necessary to make the final diagnosis, any effort should be made to come close to the 
correct diagnosis non-invasively, because the management of CTI-dependent, non-CTI-dependent AFL and atrial fibrillation by catheter ablation differ substantially.

Although cycle length (CL) of CTI-dependent AFL constitutes a fundamental descriptor, there is not detailed study describing mean CL distribution in CTIdependent AFL. To our knowledge, many previous studies concerning CTI-dependent AFL either did not report data on CL or included relatively small number of patients (Lewis et al. 1920, Olshansky et al. 1990, Feld et al. 1992, Kirkorian et al. 1994, Calkins et al. 1994, Olgin et al. 1995, Poty et al. 1995, Kalman et al. 1996, Cheng et al. 1999, Narayan et al. 2005, Santucci et al. 2009). Moreover, some of them lacked the electrophysiological confirmation of the diagnosis of CTI-dependent AFL (Lewis 1920, Wells 1979).

Therefore, our study was aimed at investigating the distribution of CTI-dependent AFL CL in a larger group of patients referred to the electrophysiological laboratory for catheter ablation of sustained CTIdependent AFL and identifying the shortest AFL CL that can be successfully treated by CTI ablation.

\section{Methods}

We retrospectively analyzed digital recordings of intracardiac electrograms in series of 121 consecutive patients referred for first radiofrequency ablation of sustained CTI-dependent AFL from January 2003 to December 2008. Both demographic and clinical data were collected from standard medical records. Standard protocol was used for the electrophysiological study and for the catheter ablation. A 20-pole 7-Fr steerable catheter with 2-10-2 mm spacing (Duodeca, Daig Corporation, Minnetonka, MN, USA) was placed in the right atrium along the tricuspid annulus and anterior to the terminal crest with the catheter tip at the inferolateral CTI. A decapolar 6-Fr steerable catheter with 2-8-2 mm spacing (Livewire CSL, Diag Corporation) was placed into the coronary sinus. A 7-Fr ablation catheter with externally irrigated 3.5-mm tip (ThermoCool, Biosense-Webster Inc., Diamond Bar, CA, USA) was placed at CTI. Diagnosis of CTI-dependent AFL was made by observation of typical pattern on the surface 12-lead ECG together with concordant activation sequence recorded from intracardiac catheters and, in majority of patients, by the demonstration of concealed entrainment from CTI with postpacing interval $<\mathrm{AFL} \mathrm{CL}+20 \mathrm{~ms}$. Diagnosis was finally supported by the specific mode of AFL termination during CTI ablation.

Prucka Cardiolab 7000 (GE Healthcare, UK) served as recording system which stored intracardiac signals at sampling frequency of $977 \mathrm{~Hz}$ with voltage resolution of $0.001 \mathrm{mV}$. Being aware of cardiac cycle and respiratory variability of AFL CL, analysis was performed in continuous 18-second segments (one segment per case) of pre-ablation atrial electrograms which were exported and digitally analyzed. Single bipolar signal from lateral right atrium and from proximal coronary sinus with the most stable electrogram morphology were selected for the analysis by a purposemade software package. Atrial electrograms were automatically detected using combination of threshold and derivative methods and their positions were adjusted by maximum correlation with signal-averaged electrogram template. All signals were carefully visually inspected and manually edited when needed. Such approach yielded $\sim 180 \mathrm{CL}$ readings from 2 sites which were finally averaged.

The mean AFL CL was calculated in subgroups according to underlying cardiac disease: hypertensives (with arterial hypertension, without structural heart disease); CAD patients (with coronary artery disease, including myocardial infarction, without history of cardiac surgery); surgery patients (after CABG and/or valve surgery) and compared with controls (without structural heart disease, without arterial hypertension). In addition, patients treated with specific antiarrhythmic drugs (AADs) (excluding beta-blockers), patients with hypertension and surgery patients were compared with the rest of the population. Mann-Whitney U-test for independent samples, Spearman's correlation analysis, Shapiro-Wilk W test, and multivariate regression analysis were used for statistical analysis as appropriate. P-value < 0.05 was considered significant.

\section{Results}

Total 121 patients (98 men; age $64 \pm 11$ years) were included to the study. Clinical data are presented in Table 1. Mean CL of all AFLs was $243 \pm 33 \mathrm{~ms}$; range 178-399 ms; mode of $223 \mathrm{~ms}$; median of $240 \mathrm{~ms}$; interquartile range (IQR) of 222-258 ms. Distribution of $\mathrm{CL}$ was not normal (Shapiro Wilk test, $\mathrm{W}=0.922$, $\mathrm{p}<0.001$ ), was skewed to the right (skewness coefficient of $1.33 \pm 0.22$ ) and had positive kurtosis (3.6 \pm 0.44$)$. Figure 1 shows the distribution of AFL CL for total population. 
Table 1: Demographics and clinical characteristics of studied population.

$\begin{array}{ll}\text { No. of patients } & 121 \\ \text { Age (mean } \pm S D) & 64 \pm 11 \text { years } \\ \text { Male } & 98(81 \%) \\ \text { LVEF (mean } \pm S D) & 54 \pm 12 \% \\ \text { CAD/MI } & 35(30 \%) / 17(14 \%) \\ \text { Arterial hypertension } & 72(59.5 \%) \\ \text { Diabetes mellitus } & 34(28 \%) \\ \text { History of atrial fibrillation } & 17(14 \%) \\ \text { or atypical AFL } & 21(17 \%) \\ \text { Previous cardiac surgery } & 12(10 \%) \\ \text { CABG } & 4(3 \%) \\ \text { Aortic valve replacement } & \\ \text { Mitral valve repair or } & 3(2.5 \%) \\ \text { replacement } & 2(1.6 \%) \\ \text { Other } & 0 \\ \text { MAZE procedure } & \\ \text { Concomitant medication } & \\ \text { None } & 22(18 \%) \\ \text { Amiodarone / sotalol } & 28(23 \%) / 3(2.5 \%) \\ \text { Propafenone } & 16(13 \%) \\ \text { beta-blockers / Ca-blockers } & 74(61 \%) / 7(6 \%) \\ \text { (verapamil) } & 11(9 \%) \\ \text { Digoxin } & \end{array}$

AFL - atrial flutter, LV EF - left ventricle ejection fraction, CAD coronary artery disease, MI - myocardial infarction, CABG coronary artery bypass grafting.

$\mathrm{CCW}$ and $\mathrm{CW}$ direction of AFL wavefront was present in $103(85.1 \%)$ and 18 (14.9\%) subjects, respectively. In 5 cases both AFL circuit directions were observed during the procedure. Both $\mathrm{CCW}$ and $\mathrm{CW}$ AFLs had comparable CL (median 240, IQR 222-258 ms vs. median 234, IQR 217-253 ms, respectively). AFL CL was significantly longer in women than in men (median 250, IQR 227-283 ms vs. median 235, IQR 220-252 ms, $\mathrm{p}=0.043$ ). However, women were significantly older than men $(71.1 \pm 7.7$ years vs. $62.8 \pm 11.5$ years, $p=0.001)$. There was weak correlation $(\mathrm{r}=0.27, \mathrm{p}<0.01)$ between age and AFL CL. After exclusion of clear outliers (the youngest patient after surgery for congenital heart disease and the patient with the longest CL after complex mitral and tricuspid valve surgery), the correlation further improved $(\mathrm{r}=0.30, \mathrm{p}<0.001)$. All patients with concomitant disease had significantly longer AFL CL than otherwise healthy persons: 34 (28\%) hypertensive patients (median 241, IQR 223-262 ms), 23 (19\%) CAD patients (median 239,

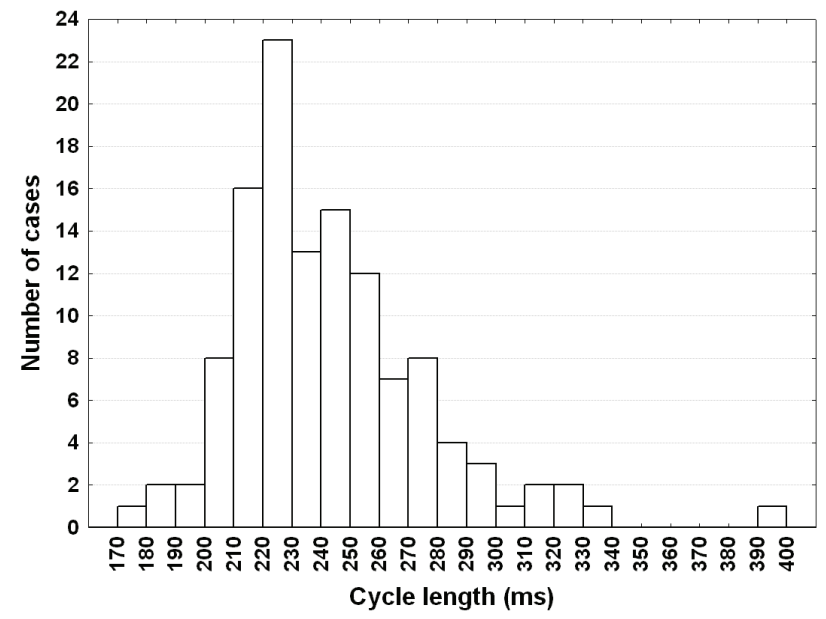

Fig. 1. Histogram of distribution of atrial flutter cycle length.

IQR 228-264 ms) and 21 (17\%) cardiac surgery patients (median 258, IQR 247-276 ms) vs. 28 (23\%) healthy controls (median 222, IQR 216-244 ms); $<<0.05$. Some patient subgroups had longer AFL CL when compared to the rest of population (Table 2). In multivariate regression analysis only age, treatment with AADs and the history of cardiac surgery were independently associated with AFL CL that increased by $6 \pm 3 \mathrm{~ms}$ per decade of age ( $p=0.036$ ), by $11 \pm 6 \mathrm{~ms}$ in the presence of AADs $(p=0.052)$, and by $26 \pm 9 \mathrm{~ms}$ in case of previous cardiac surgery $(p=0.004)$, specifically by the regression equation of AFL CL $[\mathrm{ms}]=191+0.6$. Age $[\mathrm{yrs}]+11$. AADs $[0=$ no; $1=$ yes $]+26 \cdot$ cardiac surgery $[0=$ no; $1=$ yes $]$ $(\mathrm{r}=0.43, \mathrm{p}=0.00002)$, while gender and the presence of structural heart disease were not independent covariates.

Short AFL CL $(<200 \mathrm{~ms})$ was observed in 5 (4.1\%) cases: in 2 CW AFLs (178 and $185 \mathrm{~ms})$ and in 3 CCW AFLs (186, 196 and $198 \mathrm{~ms})$. More detailed data are summarized in Table 3 . In 4 cases of AFL with $\mathrm{CL}<200 \mathrm{~ms}$ arrhythmia terminated during CTI ablation. In one patient CCW AFL (CL $198 \mathrm{~ms}$ ) converted into CW AFL during ablation with slightly longer CL (202 ms) and terminated during subsequent entrainment maneuvers. Termination of AFL with the shortest CL during CTI ablation is shown in Figure 2.

Only 1 of 78 AFLs (1.3\%) in patients with age $>60$ years had $\mathrm{CL}<200 \mathrm{~ms}$ compared to 4 of 43 AFLs $(9.3 \%)$ in patients with age $\leq 60$ years $(\mathrm{p}<0.05)$.

\section{Discussion}

This is single-center, retrospective study which demonstrated that distribution of CL in CTI-dependent 
Table 2. Differences in AFL CL for subgroups of patients versus the rest of population.

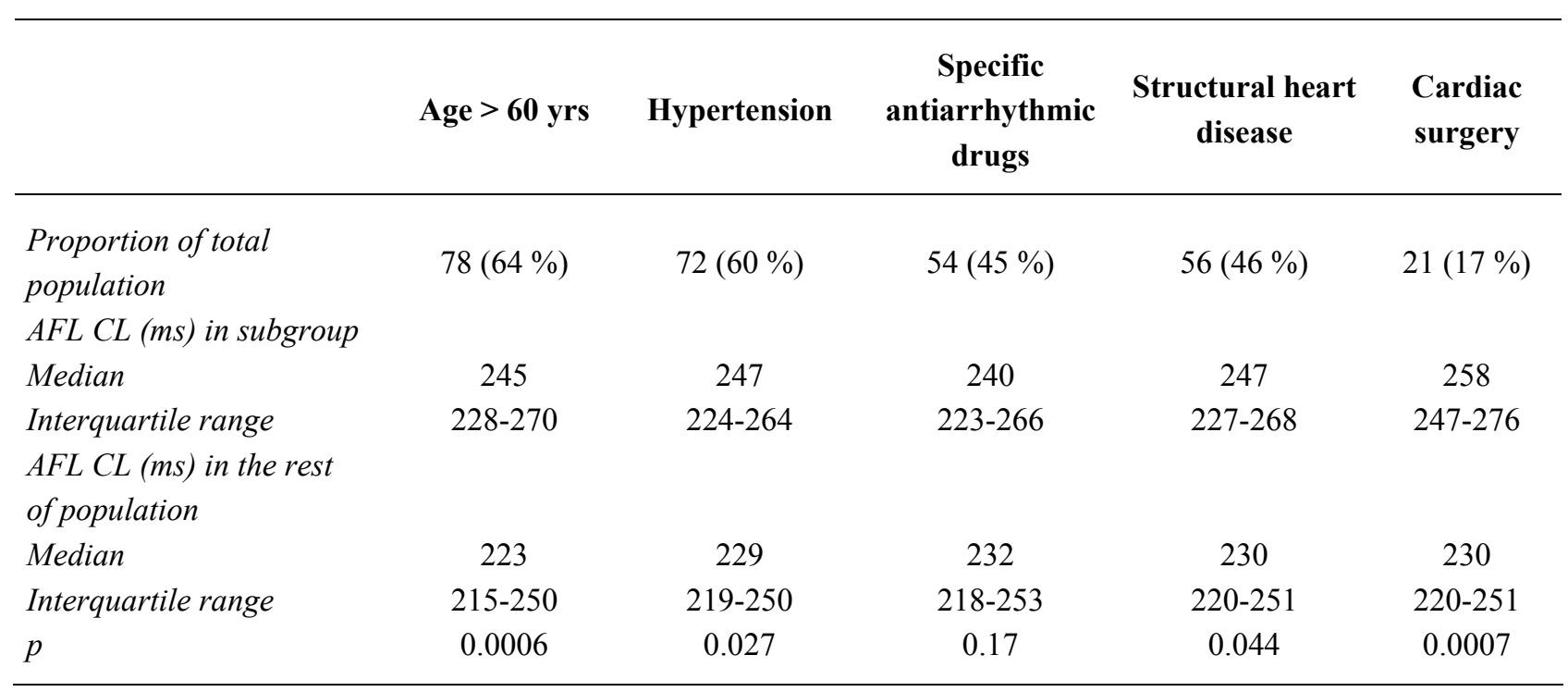

$\mathrm{AFL}-$ atrial flutter, $\mathrm{CL}$ - cycle length.

Table 3. Baseline characteristics of patients with AFL $C L<200$ ms.

\begin{tabular}{lccccc}
\hline Patient \# & $\mathbf{1}$ & $\mathbf{2}$ & $\mathbf{3}$ & $\mathbf{4}$ & $\mathbf{5}$ \\
\hline Cycle length (ms) & 178 & 185 & 186 & 198 & 196 \\
Gender & Male & Male & Male & Female & Male \\
Age (years) & 60 & 50 & 46 & 74 & 49 \\
Direction of AFL & $\mathrm{CW}$ & $\mathrm{CW}$ & $\mathrm{CCW}$ & $\mathrm{CCW}$ & CCW \\
Termination of AFL & Catheter & Catheter & Catheter & Catheter & Conversion to \\
Arterial hypertension & ablation & ablation & ablation & ablation & CW AFL \\
SHD & Yes & Yes & No & Yes & Yes \\
LV EF & DCM & No & No & CAD / MI & CAD \\
Previous cardiac surgery & $30 \%$ & $45 \%$ & $50 \%$ & $60 \%$ & $60 \%$ \\
Antiarrhythmic drugs & No & No & No & No & CABG \\
History of atrial fibrillation or & No & $\beta$-blockers & $\beta$-blockers & $\beta$-blockers & Propafenone \\
atypical AFL & No & No & No & No & No \\
\hline
\end{tabular}

$\mathrm{AFL}$ - atrial flutter, $\mathrm{CL}$ - cycle length, CW - clockwise, CCW - counterclockwise, SHD - structural heart disease, LV EF - left ventricle ejection fraction, DCM - dilated cardiomyopathy, CAD - coronary artery disease, MI - myocardial infarction, CABG - coronary artery bypass grafting.

AFL is not normal, asymmetric with right-skewed pattern with an excess of values around the mean (excessive peakedness) and at the extremes (heavy tails). This is not surprising because AFL CL depends on conduction velocity and size of the reentry circuit. The shortest $C L$ is constrained by the existence of anatomical or functional barriers bounding AFL circuit and limited by maximum velocity of wave front propagation in atria (Waxman et al. 1991). On the other hand, the longest CL is theoretically unlimited depending on the presence of significant zone of slow conduction. Interestingly, distribution of CTI-dependent AFL CL has not been previously studied in detail. Table 4 summarizes relatively small studies that reported the range of CTIdependent AFL CL from $171 \mathrm{~ms}$ to $350 \mathrm{~ms}$, i.e. 171-350 bpm. Extremely short CL has been documented only in two studies (Lewis et al. 1920, Wells et al. 1979). In both studies the diagnosis of CTI-dependent AFL was solely based on surface ECG so that it cannot be ruled out that these studies included non-CTI-dependent arrhythmia 


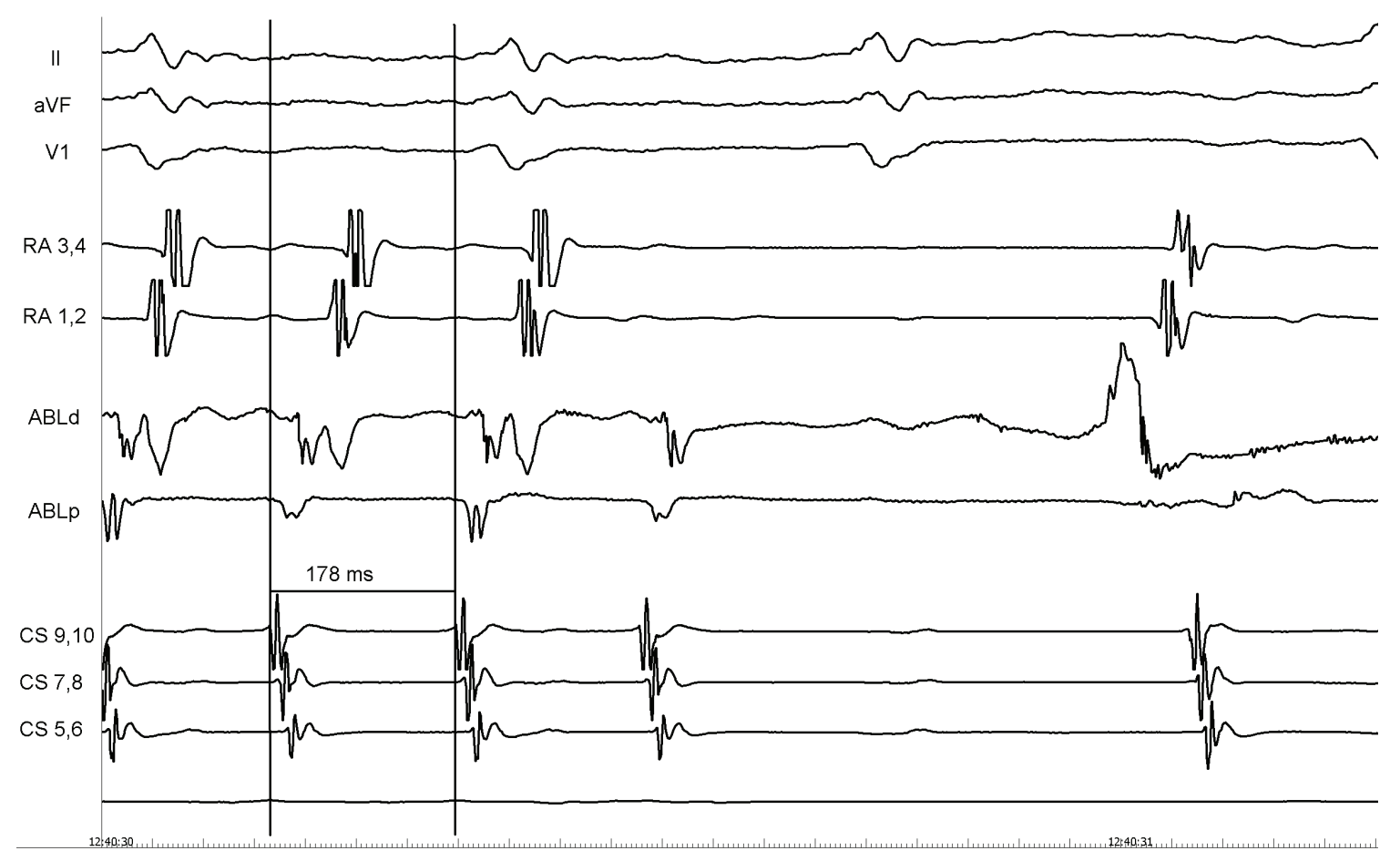

Fig. 2. Example of intracardiac signals during catheter ablation of $\mathrm{CW} A F L$ with the shortest $\mathrm{CL}(178 \mathrm{~ms})$ at the moment of its termination. The AFL CL is marked with vertical lines. Note the missing second component of double potential in ABLd at the moment of flutter termination. II, aVF, V1 - surface ECG leads, RA - low lateral right atrium, ABLd a ABLp - ablation catheter distal and proximal pole, CS - coronary sinus.

like atypical AFL or even organized atrial fibrillation. Total 233 patients with more clearly defined CTIdependent AFL were investigated in remaining 11 studies (Table 4) with CL range 190-350 ms, i.e. 171-316 bpm. While only in 1 of 233 cases (Calkins 1994) the CL was $<200 \mathrm{~ms}$, we identified $4 \%$ of all AFLs having $\mathrm{CL}<200 \mathrm{~ms}$ in our study. Two explanations for this discrepancy may be offered. First, selection of patients for some of former studies, which were not designed to investigate the distribution of AFL CL, were likely biased towards clear CTI-dependent AFLs with relatively long CL. Second, in our study, the CL assessment was performed with an accuracy of $\sim 1 \mathrm{~ms}$ while in previous studies the mean CL was rounded to $10-\mathrm{ms}$ multiples. That is why not 5 but only 3 AFL cases (all with age $\leq 60$ years) can be considered as having the CL clearly $<200 \mathrm{~ms}$ in our study. Although the number of patients is limited to assess exactly the lowest margin for AFL CL, the study documents existence of CTI-dependent AFL with rather short CL.

Nevertheless, there is considerable disagreement between finding of this study (and other mentioned studies) and the CTI-dependent AFL frequency of 240$350 \mathrm{bpm}$, i.e. CL of $171-250 \mathrm{~ms}$, which is frequently reverberated in cardiology/electrophysiology textbooks. It should be stressed, that CTI-dependent AFL frequency $>300 \mathrm{bpm} \quad(\mathrm{CL}<200 \mathrm{~ms})$ is extremely rare, while significant proportion of AFLs (36\% in our series) has CL $>250$ ms. Seemingly, neither very short nor excessively long CL can serve as a reliable marker of non-CTI-dependent AFL or focal atrial tachycardia. Since CTI-dependent AFL may also have an atypical surface ECG pattern (Barbato et al. 2009) and eccentric coronary sinus activation (Oshikawa et al. 2002), it is believed that entrainment from the CTI should be performed prior to transseptal puncture in all patients with apparently left AFL.

Aging is a known factor influencing atrial electrophysiological properties, specifically, slowing of intra-atrial conduction, which can give rise to the initiation of reentry. Accordingly, we have found positive correlation between AFL CL and age. Further, it is known that AFL is more prevalent in men than in women (Granada et al. 2000) and women are usually older at the time of presentation (Humphries et al. 2004). Also these facts are well in line with our data. In the present study, women had longer AFL CL than men. This difference, however, resulted from excessively prolonged AFL CL in 
Table 4. List of previously published reports on CTI-dependent AFL.

\begin{tabular}{cccll}
\hline $\begin{array}{c}\text { Mean AFL CL } \\
(\mathbf{m s})\end{array}$ & $\begin{array}{c}\text { CL range } \\
(\mathbf{m s})\end{array}$ & $\begin{array}{c}\text { Frequency range } \\
(\mathbf{b p m})\end{array}$ & N pts & Author and date \\
\hline- & $171-250$ & $240-350$ & - & Lewis et al. $(1920)$ \\
205 & $177-250$ & $240-338$ & 18 & Wells et al. $(1979)$ \\
$235 \pm 27$ & $205-290$ & $207-293$ & 10 & Olshansky et al. $(1990)$ \\
$253 \pm 39$ & $200-350$ & $171-200$ & 12 & Feld et al. $(1992)$ \\
$258 \pm 44$ & $190-320$ & $187-315$ & 16 & Calkins et al. $(1994)$ \\
$246 \pm 26$ & $200-320$ & $187-300$ & 19 & Kirkorian et al. $(1994)$ \\
$258 \pm 26$ & $220-290$ & $210-270$ & 8 & Olgin et al. $(1995)$ \\
- & $205-310$ & $193-293$ & 12 & Poty et al. $(1995)$ \\
$258 \pm 24$ & $216-292$ & $205-278$ & 13 & Kalman et al. $(1996)$ \\
$270 \pm 40$ & - & - & 28 & Cheng et al. $(1999)$ \\
$247 \pm 31$ & $>200$ & $<300$ & 39 & Narayan et al. $(2005)$ \\
$250 \pm 29$ & $210-325$ & $185-286$ & 50 & Maury et al. $(2008)$ \\
$261 \pm 40$ & - & - & 26 & Santucci et al. $(2009)$ \\
\hline
\end{tabular}

$\mathrm{AFL}-$ atrial flutter, $\mathrm{CL}$ - cycle length.

8 women of advanced age, who had undergone cardiac surgery. This is in agreement with the results of multivariate analysis which showed that longer AFL CL in women was not gender-related. However, proportion of woman in study population was low to draw any general conclusions about gender difference in AFL CL.

Cardiac surgery was the strongest factor independently associated with longer AFL CL. Presence of advanced right atrium scarring as a result of right atrium cannulation or incision may be the explanation because majority of procedures were performed „onpump“. Nevertheless, AFL CL $<200$ ms was also present in one patient after cardiac surgery (CABG). Therefore, short AFL CL does not preclude the possibility of CTIdependent AFL even in cases with a history of previous cardiac surgery.

Antiarrhythmic medication affects AFL CL. Acute administration of propafenone prolonged the AFL $\mathrm{CL}$ to a greater extent than did amiodarone or ibutilide (Tai et al. 1998). An impact of chronic AADs medication on AFL CL in our study seemed to be minor compared to the effects of aging and underlying heart disease.

Both CCW and CW CTI-dependent AFL had comparable CL. This finding is in agreement with previous studies (Friedman et al. 2000, Marine et al. 2001). However, we cannot rule out the possibility that our study also included the variant form of CTI dependent AFL, termed "lower loop reentry" (LLR). Compared to CTI-dependent AFL, LLR utilizes the conduction gap in terminal crest leading to short-cutting of the AFL circuit (Cheng et al. 1999, Zhang et al. 2004). Thus, not surprisingly, previous studies showed that CL in LLR was significantly shorter than that in CTIdependent AFL (Cheng et al. 1999, Yang et al. 2001). Due to the retrospective nature of the present study, we were not able to differentiate between CTI-dependent AFL and LLR variant. Analogically, we did not study the active circuit course in the upper portion of right atrium, where substantial variability exists (Santucci et al. 2009) which can significantly affect the AFL CL. However, successful therapy of all forms of CTI-dependent AFL (including LLR) is based on achievement of conduction block across the CTI without need for detailed discrimination between these subtypes. We therefore believe that this limitation did not lead to any bias in the data analysis and practical implications.

Short-term variability of AFL CL can be influenced by various maneuvers that change right atrial volume and, thus, have a direct effect on AFL circuit size (Waxman et al. 1991, Ravelli et al. 2008, Mase et al. 2009). Unlike atrial fibrillation, where vagal excitation is associated with shortening of dominant fibrillatory CL (Takahashi et al. 2006), the CL of AFL, arrhythmia with fully excitable gap, is independent of autonomic modulation. At resting conditions, ventriculophasic and respiratory-synchronous variations in AFL CL prevail. Their impact on results of the present study was minimized by analysis of sufficiently long segment 
covering several respiratory cycles.

Co-incidence of AFL and atrial fibrillation is high. Previous studies have documented various degree of left-to-right atrium gradient of dominant frequency during sustained atrial fibrillation (Lazar et al. 2004). Presence of spatiotemporal organization of fibrillatory activity can mimic both $\mathrm{CW}$ and $\mathrm{CCW}$ AFL pattern on surface ECG. Similarly, extensive catheter ablation in left atrium alters ECG morphology of newly developed CTIdependent AFL (Chyou et al. 2010, Shah 2011). Noninvasive differentiation of CTI-dependent AFL and atrial fibrillation is crucial for effective workflow in EP laboratory because of completely different management of both arrhythmias. New ECG-based methods were recently introduced to make correct AFL diagnosis prior to invasive electrophysiological study. Spectral ECG analysis and wavefront variability analysis were shown to be useful tools in identification differences in CTIdependent and non-CTI-dependent AFL versus atrial fibrillation when visual separation is difficult (Hoppe et al. 2005). Although sophisticated methods might be helpful, simple manual measurement of AFL CL using surface ECG can be also useful. Measurement of AFL CL from standard ECG is possible with accuracy $\pm 2 \mathrm{~ms}$ when assessed over 10 AFL waves which is critical for short AFL CL. According to the results of this study when AFL CL is found $<200 \mathrm{~ms}$, particularly in elderly patients, the diagnosis of CTI-dependent AFL is doubtful. In conclusion, the study described the distribution of AFL CL in larger cohort of patients with strict electrophysiological confirmation of CTI-dependent AFL. It confirmed that very short CL does not rule out the possibility of CTI-dependency. At the same time, such situation is quite rare, especially in elderly patients. This may have practical implications for the management of patients with suspected CTI-dependent AFL.

\section{Conflict of Interest}

There is no conflict of interest.

\section{Acknowledgements}

Supported by the cardiovascular research project \#MSM0021620817 „Invasive approach to myocardial salvage and regeneration" of the Charles University, Prague, Czech Republic.

\section{References}

BARBATO G, CARINCI V, TOMASI C, FRASSINETI V, MARGHERI M, DI PASQUALE G: Is electrocardiography a reliable tool for identifying patients with isthmus-dependent atrial flutter? Europace 11: 1071-1076, 2009.

CALKINS H, LEON AR, DEAM AG, KALBFLEISCH SJ, LANGBERG JJ, MORADY F: Catheter ablation of atrial flutter using radiofrequency energy. Am J Cardiol 73: 353-356, 1994.

CHENG J, CABEEN WR, SCHEINMAN MM: Right atrial flutter due to lower loop re-entry mechanism and anatomic substrates. Circulation 99: 1700-1705, 1999.

CHYOU JY, HICKEY K, DIAMOND L, WHANG W, DIZON J, GARAN H, BIVIANO A: Atypical electrocardiographic features of cavotricuspid isthmus-dependent atrial flutter occurring during left atrial fibrillation ablation. Ann Noninvasive Electrocardiol 15: 200-208, 2010.

COSIO FG, LOPEZ-GIL M, GOICOLEA A, ARRIBAS F, BARROSO JL: Radiofrequency ablation of the inferior vena cava-tricuspid valve isthmus in common atrial flutter. Am J Cardiol 71: 705-709, 1993.

FELD GK, FLECK RP, CHEN PS, BOYCE K, BAHNSON TD, STEIN JB, CALISI CM, IBARRA M: Radiofrequency catheter ablation for the treatment of human type 1 atrial flutter. Identification of a critical zone in the reentrant circuit by endocardial mapping techniques. Circulation 86: 1233-1240, 1992.

FRIEDMAN PA, LURIA D, FENTON AM, MUNGER TM, JAHANGIR A, SHEN WK, REA RF, STANTON MS, HAMMILL SC, PACKER DL: Global right atrial mapping of human atrial flutter: the presence of posteromedial (sinus venosa region) functional block and double potentials: a study in biplane fluoroscopy and intracardiac echocardiography. Circulation 101: 1568-1577, 2000.

FUKUZAWA K, YOSHIDA A, KUBO S, TAKANO T, KIUCHI K, KANDA G, TAKAMI K, KUMAGAI H, TORII S, TAKAMI M, OHNISHI Y, OKAJIMA K, HIRATA K: Upper turnover portion of the reentry circuit for typical and reverse typical atrial flutter. Pacing Clin Electrophysiol 31: 1160-1167, 2008. 
GAMI AS, EDWARDS WD, LACHMAN N, FRIEDMAN PA, TALREJA D, MUNGER TM, HAMMILL SC, PACKER DL, ASIRVATHAM SJ: Electrophysiological anatomy of typical atrial flutter: The posterior boundary and causes for difficulty with ablation. J Cardiovasc Electrophysiol 21: 144-149, 2010.

GRANADA J, URIBE W, CHYOU PH, MAASSEN K, VIERKANT R, SMITH PN, HAYES J, EAKER E, VIDAILLET H: Incidence and predictors of atrial flutter in the general population. $J$ Am Coll Cardiol 36: 2242-2246, 2000.

HOPPE BL, KAHN AM, FELD GK, HASSANKHANI A, NARAYAN SM: Separating atrial flutter from atrial fibrillation with apparent electrocardiographic organization using dominant and narrow f-wave spectra. $J \mathrm{Am}$ Coll Cardiol 46: 2079-2087, 2005.

HUMPHRIES KH, JACKEVICIUS C, GONG Y, SVENSEN L, COX J, TU JV, LAUPACIS A: Canadian Cardiovascular Outcomes Research Team. Population rates of hospitalization for atrial fibrillation/flutter in Canada. Can J Cardiol 20: 869-876, 2004.

KALMAN JM, OLGIN JE, SAXON LA, FISHER WG, LEE RJ, LESH MD: Activation and entrainment mapping defines the tricuspid annulus as the anterior barrier in typical atrial flutter. Circulation 94: 244-246, 1996.

KIRKORIAN G, MONCADA E, CHEVALIER P, CANU G, CLAUDEL JP, BELLON C, LYON L, TOUBOUL P: Radiofrequency ablation of atrial flutter efficacy of an anatomically guided approach. Circulation 90: 28042814, 1994.

LAZAR S, DIXIT S, MARCHLINSKI FE, CALLANS DJ, GERSTENFELD EP: Presence of left-to-right atrial frequency gradient in paroxysmal but not persistent atrial fibrillation in humans. Circulation 110: 3181-3186, 2004.

LEWIS T, FEIL HS, STROUD WD: Observations upon flutter and fibrillation. Part II. The nature of auricular flutter. Part III: Some effects of rhythmic stimulation of the auricle. Heart 7: 191-223, 1920.

MARINE JE, KORLEY VJ, OBIOHA-NGWU O, CHEN J, ZIMETBAUM P, PAPAGEORGIOU P, MILLIEZ P, JOSEPHSON ME: Different patterns of interatrial conduction in clockwise and counterclockwise atrial flutter. Circulation 104: 1153-1157, 2001.

MASE M, DISERTORI M, RAVELLI F: Cardiorespiratory interactions in patients with atrial flutter. $J$ Appl Physiol 106: 29-39, 2009.

MAURY P, DUPARC A, HEBRARD A, EL BAYOMY M, DELAY M: Prevalence of typical atrial flutter with reentry circuit posterior to the vena cava. Use of entrainment at the atrial roof. Europace 10: 190-196, 2008.

NARAYAN SM, HASSANKHANI A, FELD G, BHARGAVA V: Separating non-isthmus from isthmus dependent atrial flutter using wavefront variability. J Am Coll Cardiol 45: 1269-1279, 2005.

OLGIN JE, KALMAN JM, FITZPATRICK AP, LESH MD: Role of right atrial endocardial structures as barriers to conduction during human type 1 atrial flutter. Activation and entrainment guided by intracardiac echocardiography. Circulation 92: 1839-1848, 1995.

OLSHANSKY B, OKUMURA K, HENTHORN RW, WALDO AL: Characterization of double potentials in human atrial flutter: studies during transient entrainment. $J$ Am Coll Cardiol 15: 833-841, 1990.

OSHIKAWA N, WATANABE I, MASAKI R, OKUMURA Y, OKUBO K, SUGIMURA H, KOJIMA T, SAITO S, OZAWA Y, KANMATSUSE K: Relationship between polarity of the flutter wave in the surface ECG and endocardial atrial activation sequence in patients with typical counterclockwise and clockwise atrial flutter. J Interv Card Electrophysiol 7: 215-223, 2002.

POTY H, SAOUDI N, ABDEL AA, NAIR M, LETAC B: Radiofrequency catheter ablation of type 1 atrial flutter. Prediction of late success by electrophysiological criteria. Circulation 92: 1389-1392, 1995.

RAVELLI F, MASE M, DISERTORI M: Mechanical modulation of atrial flutter cycle length. Prog Biophys Mol Biol 97: 417-434, 2008.

SANTUCCI PA, VARMA N, CYTRON J, AKAR J, WILBER DJ, AL CHEKAKIE MO, BRYSIEWICZ N: Electroanatomic mapping of postpacing intervals clarifies the complete active circuit and variants in atrial flutter. Heart Rhythm 6: 1586-1595, 2009.

SHAH DC, JAIS P, HAISSAGUERRE M, CHOUAIRI S, TAKAHASHI A, HOCINI M, GARRIGUE S, CLÉMENTY J: Three-dimensional mapping of the common atrial flutter circuit in the right atrium. Circulation 96: 3904-3912, 1997. 
SHAH DC: Twelve-lead ECG interpretation in a patient with presumed left atrial flutter following AF ablation. J Cardiovasc Electrophysiol 22: 613-617, 2011.

TAI CT, CHEN SA, FENG AN, YU WC, CHEN YJ, CHANG MS: Electropharmacologic effects of class I and class III antiarrhythmic drugs on typical atrial flutter. Insights into the mechanism of termination. Circulation 97: 19351945, 1998.

TAKAHASHI Y, JAIS P, HOCINI M, SANDERS P, ROTTER M, ROSTOCK T, HSU LF, SACHER F, CLÉMENTY J, HAÏSSAGUERRE M: Shortening of fibrillatory cycle length in the pulmonary vein during vagal excitation. $J$ Am Coll Cardiol 47: 774-780, 2006.

WALDO AL, MACKALL JA, BIBLO LA: Mechanisms and medical management of patients with typical atrial flutter. Cardiol Clin 15: 661-676, 1997.

WALDO AL: Treatment of atrial flutter. Heart 84: 227-232, 2000.

WAXMAN MB, YAO L, CAMERON DA, KIRSH JA: Effects of posture, Valsalva maneuver and respiration on atrial flutter rate: an effect mediated through cardiac volume. J Am Coll Cardiol 17: 1545-1552, 1991.

WELLS JL Jr, MACLEAN WA, JAMES TN, WALDO AL: Characterization of atrial flutter. Studies in man after open heart surgery using fixed atrial electrodes. Circulation 60: 665-673, 1979.

YANG Y, CHENG J, BOCHOEYER A, HAMDAN MH, KOWAL RC, PAGE R, LEE RJ, STEINER PR, SAXON LA, LESH MD, MODIN GW, SCHEINMAN MM: Atypical right atrial flutter patterns. Circulation 103: 3092-3098, 2001.

ZHANG S, YOUNIS G, HARIHARAN R, HO J, YANG Y, IP J, THAKUR RK, SEGER J, SCHEINMAN MM, CHENG J: Lower loop reentry as a mechanism of clockwise right atrial flutter. Circulation 109: 1630-1635, 2004. 